\title{
UN NUEVO EJEMPLO DE ARQUITECTURA GÓTICA EN MELILLA: LA DESAPARECIDA IGLESIA DE SAN MIGUEL
}

\section{A NEW EXAMPLE OF GOTHIC ARCHITECTURE IN MELILLA: THE DISAPPEARED CHURCH OF SAN MIGUEL}

\author{
Antonio Bravo Nieto \\ (UNED, España) \\ abravo@melilla.uned.es \\ Sergio Ramírez González \\ (Universidad de Málaga, España) \\ srg@uma.es
}

Recibido: 30 de junio 2020 / Aceptado: 27 de agosto 2020

\begin{abstract}
Resumen: El presente artículo intenta documentar y precisar diferentes aspectos sobre una arquitectura religiosa del siglo XVI: la iglesia de San Miguel de Melilla. Este edificio, ya desaparecido, presentaba la singularidad de ser uno de los escasos ejemplos del gótico tardío construidos en el continente africano, por lo que viene a sumarse a otras obras levantadas por españoles y portugueses en este contexto geográfico. Explicar su origen, principales vicisitudes y, finalmente, cómo fue demolida para levantar una iglesia nueva, son objetivos de este trabajo, así como documentar los vestigios todavía existentes de la antigua construcción que nos permiten apreciar algunas de sus características.
\end{abstract}

Palabras clave: arquitectura gótica; norte de África; arquitectura religiosa; Melilla

\begin{abstract}
This article intends to illustrate and list several features of a religious oriented architecture reflected in the 16th century San Miguel church of Melilla (North Africa). The church from which almost nothing remains, was a very peculiar building since it was one of the few examples among those built by Portuguese and Spaniards of clear late Gothic style in the African continent. To describe its origins, its different ups and downs and eventually how it was demolished so to give room to a new church are the main goals
\end{abstract}


of this paper. We will also list all the elements that we could still observe on location that make us guess how magnificent this building was.

Keywords: gothic architecture; north Africa; religious architecture; Melilla

\section{Introducción}

Durante muchos años, todo lo concerniente a la iglesia de San Miguel de Melilla (siglo XVI) ha sido un capítulo muy poco conocido dentro de la historia de la arquitectura religiosa de la ciudad. La incertidumbre se cernía sobre su cronología e incluso sobre su misma ubicación (Estrada, 1768, p. 541) ${ }^{1}$, lo que determinaba que muchos datos documentales históricos no pudieran ser evaluados de una manera efectiva. Actualmente, y a la luz de la revisión de las fuentes documentales y de las últimas aportaciones arqueológicas, podemos adelantar una cronología más o menos clara sobre cuándo fue construida y por qué se produjo su final, además de confirmar dónde estuvo realmente ubicada, estudiando algunos de sus vestigios existentes en el interior de la actual iglesia de la Purísima Concepción.

\section{Arquitectura gótica en África}

Fue la penetración portuguesa y española en África en los siglos XV y XVI (sobre todo en el norte del continente y en otros puntos costeros e insulares) la que permitió la aparición de arquitecturas europeas vinculadas habitualmente con la fortificación, aunque también con otras tipologías más funcionales caso de almacenes, aljibes y edificaciones religiosas.

La lista de obras nos llevaría a Ceuta, Alcazarseguer, Tánger, Arcila, Azemur, Mazagán, Safi y Mogador, y con mayor lejanía a Cabo Verde, Congo o Mozambique. En la casi totalidad de ellas podemos encontrar arquitecturas muy influenciadas por el estilo gótico manuelino, en base a su origen portugués. Y destacaremos en este conjunto, por la relación con el trabajo que aquí presentamos, las que aparecen vinculadas al gótico tardío que precede la llegada de los modelos arquitectónicos renacentistas a este continente. Nos referimos especialmente a los restos de la catedral de Safi (Marruecos), al baptisterio de

\footnotetext{
${ }^{1} \mathrm{Al}$ respecto es muy significativo lo que decía Juan Antonio de Estrada, el principal historiador de la ciudad en el siglo XVIII: «había otra (iglesia) antigua en la calle de San Miguel que fue arruinada».
} 
la iglesia de nuestra Señora del Rosario de Cidade Velha en Cabo Verde o a la capilla de Nuestra Señora del Baluarte, en el fuerte de San Sebastián de Mozambique, todas con bóvedas góticas estrelladas (Carabelli, 2012) (Correia \& Teixeira, 2019) (Darias, 2012, p. 139-148) (Mendes, 2019) (Ramos et al., 2010).

En este caso resulta también paradigmática la capilla gótica de Santiago de Melilla (Bravo, 2002, p. 36-41), con bóveda nervada de terceletes, y más recientemente la aportación documental y el estudio de vestigios realizados sobre la iglesia Mayor de Orán (Argelia), que contó con estructuras góticas en su cabecera (Ramírez \& Bravo, 2020). La iglesia de San Miguel que estudiamos en el presente trabajo, formaría parte de este ciclo constructivo que todavía mantenía en la primera mitad del siglo XVI unas formas heredadas del Gótico y que muestra sus últimos reflejos antes de la llegada de los modelos renacentistas.

\section{La primera iglesia de Melilla}

Cuando los españoles llegan a Melilla en 1497, se determina la construcción de una iglesia. En el Asiento hecho el 13 de abril de 1498 con la real hacienda por el duque de Medina Sidonia D. Juan Alonso de Guzmán, sobre la tenencia de Melilla, se determinaba el libramiento de un millón de maravedíes para las diferentes obras que había que acometer, entre ellas, la iglesia, así como la obligación de que hubiera dos clérigos para su servicio ${ }^{2}$.

Es posible que se pudieran reaprovechar o reconstruir algunos edificios del periodo musulmán anterior, aunque Rafael Gutiérrez (1993, p. 89-90) defiende que la ciudad estaba realmente semiderruida y hubo que trazar calles y levantar nuevos edificios. En concreto, para las obras de la iglesia se enviaron excepcionalmente 10.000 tejas, cuando lo que se hizo normalmente en estos momentos fue cubrir los edificios con terrado plano.

Esta iglesia va a permanecer en pie durante el primer cuarto del siglo XVI, pero debido a necesidades defensivas, y en concreto al plan de obras que se lleva a cabo sobre la ciudad en 1525, hubo de ser demolida. La razón es que el emperador Carlos V decidió

\footnotetext{
${ }^{2}$ A lo largo de este trabajo utilizaremos el trabajo inédito de José Luis Blasco López (2020) Presencia de las órdenes religiosas e iglesia católica en el norte de África: el cristianismo en Melilla, que ha tenido la cortesía de permitirnos consultar.
} 
reducir el perímetro amurallado de Melilla, de forma que la ciudad se replegó hacia el peñón rocoso, trazando una nueva muralla conocida como frente de Tierra. El nuevo recinto fue llamado Villa Nueva, y la parte de ciudad semiabandonada recibiría el nombre de Villa Vieja, que era precisamente el lugar donde se encontraba esta primera iglesia (Bravo, 1991, p. 25-45) (Castries, 1921, p. XXIII). Así aparecía recogido en el asiento que se tomó con el duque de Medina Sidonia para la tenencia de Melilla, donde se daba cuenta de su demolición, y al mismo tiempo se solicitaba construir un templo nuevo ${ }^{3}$. Esta primera iglesia fue calificada como edificio «suntuoso» en la documentación de la época ${ }^{4}$ y la piedra resultante del derribo se utilizó en diferentes obras de fortificación.

Sin embargo, la demolición no debió ser total, por cuanto todavía quedaban algunos restos cuando llega a la ciudad Miguel de Perea en 1549. En una carta de 21 de marzo de ese mismo año dice que «lo más estrecho de la Villa Vieja que viene a salir por junto a la iglesia vieja, que mañana, plaziendo a Dios la encomiença la he de echar por el suelo» ${ }^{5}$. El texto hace referencia a las demoliciones que Perea tuvo que acometer en la Villa Vieja, y nos puede revelar que algunos restos del templo todavía subsistían. En ningún caso está documentando ni puede interpretarse que se hubiera construido otra iglesia, menos aún en el mismo sitio donde se había ordenado demolerla por su inadecuado emplazamiento.

\section{San Miguel, ¿ermita o iglesia?}

Es muy razonable pensar que como la nueva iglesia que debía sustituir a la destruida no se comenzaba, surgieran otros edificios y espacios que en cierto modo suplieran las necesidades religiosas de la población (Blasco, 1989, p. 27-56) (Blasco \& Peregrina, 2001, p. 333-348) (Morales, 1921, p. 307-310) (Ramírez, 2013, p. 24-72) (Ramírez, 2014, p. 17-24). La cronología de inicio de estos edificios es difícil establecerla con precisión, pero su fábrica debió realizarse inmediatamente después de 1525. Es cierto que al mediar el siglo ya conocemos la existencia de varias ermitas en la llamada Villa Nueva: más

\footnotetext{
${ }^{3}$ Archivo General de Simancas (AGS), Guerra y Marina (GyM), leg. 39, 76, Traslado del asiento que se tomó con el duque de Medina Sidonia para la tenencia de Melilla, 1525. Este documento incluye un capítulo sobre el derribo de la iglesia anterior y solicitud para construir una nueva. También AGS, GyM, leg. 18, 42, 1540: «Para hacer la obra nueva se despobló y derribó la iglesia y casa de los capitanes que estaban en lo que se dejó, y el pueblo no tiene iglesia ni posibilidad para hacerla. Han suplicado a S.M. la mande hacer, pues la mandó dejar fuera. En la verdad, hay de ella gran necesidad».

${ }^{4}$ AGS, GyM, leg. 40, folio 33, 23 de marzo de 1550.

${ }^{5}$ Nota mecanografiada procedente del AGS, Estado, leg. 474. Archivo Cronista Oficial de Melilla (ACOM).
} 
antiguas las de San Miguel y Santa Bárvola y más reciente la capilla de Santiago, levantada en 1551. Posteriormente, aun dentro del siglo XVI, se construirían la ermita de la Victoria en la Villa Vieja (Fernández de Castro, 1941, p. 12-17) y la capilla de la Enramada en la Villa Nueva.

Como la iglesia parroquial seguía sin construirse, fue la ermita de más capacidad, San Miguel, la que asumió la función de iglesia parroquial. Resulta muy esclarecedor que el primer asiento que se realiza en el Libro Sacramental de Bautizados (González, 2001, p. 49-70) ${ }^{6}$ (Salafranca, 1985, p. 191-197) tiene fecha de 4 de julio de 1535, cuando el cura párroco Cristóbal Rodríguez bautizó a una niña con el nombre de Leonor. Esta fecha de 1535 es perfectamente viable con la posible conversión de la ermita de San Miguel en iglesia parroquial de Melilla. Por ese tiempo comenzaría su andadura como templo principal de la ciudad con la facultad de asumir los distintos sacramentos.

Un tema importante que hay que esclarecer es el relativo al autor material (el maestro de obras, ingeniero o arquitecto) que hizo la ermita de San Miguel. Por entonces ejercía como maestro mayor de Melilla Sancho de Escalante (Bravo, 2013, p. 451-452), que ya había trabajado en Granada. Tenemos noticias de su presencia en la ciudad norteafricana a partir de $1533^{7}$, aunque pudo estar antes, y sus trabajos se continúan en años posteriores $^{8}$. Su hijo Melchor ${ }^{9}$ afirmaba en 1588 que Escalante había servido cuarenta años de maestro mayor de Melilla, y aunque este tipo de afirmaciones podían ser exageradas, lo cierto es que le vincula con todos los trabajos de la ciudad durante buena parte de la primera mitad del siglo XVI. También señalaremos que sería el maestro mayor que realizó, con la dirección de Miguel de Perea, la capilla de Santiago, lo que delata que dominaba bien la construcción arquitectónica y con sobrada capacidad para levantar una bóveda gótica nervada de buena sillería.

La fábrica de San Miguel es por tanto coetánea con la presencia en Melilla del maestro mayor Sancho de Escalante, a la sazón técnico que dirigió todas las obras de la ciudad durante este periodo. Siendo por tanto el director de los trabajos, no sabemos si le

\footnotetext{
${ }^{6}$ Este investigador señala que no será hasta 1580 cuando aparezca mencionada expresamente como iglesia de San Miguel en los libros de bautizos. No obstante, aparece citada desde 1550 en otros documentos.

${ }^{7}$ AGS, libro 8, 1533-1535, documento 26, Asiento con Sancho de Escalante sobre las obras de Melilla, 1510-1534; AGS, libro 8, 1533-1535, documento 26.

${ }^{8}$ AGS, Secretaria de Estado, serie I Corona de Castilla y serie 8 Costas de África y Levante, 1536, legajo 50-3, Asiento tomado con Sancho de Escalante sobre las obras; y legajo 50-4, 23 de febrero de 1536. AGS, GyM, leg. 21, 19 de noviembre de 1541, Relación de la obra que ha hecho Sancho de Escalante en Melilla.

${ }^{9}$ AGS, GyM. leg. 241, folio 14 a 17.
} 
corresponde también la autoría del proyecto. Aunque es muy probable que fuera él mismo, no puede descartarse que obedeciera a unas trazas llevadas a cabo por alguno de los ingenieros que pasaron por Melilla durante estos años (Gabriel Tadino de Martinengo en 1527 o Micer Benedeto de Ravena en 1534) y ejecutada por Escalante (Bravo, 1991, p. 25-45).

De todas formas, la utilización de San Miguel como iglesia parroquial, se vio con visos de provisionalidad, al menos durante muchos decenios del XVI. Desde la demolición de la iglesia de la Villa Vieja, en numerosos documentos encontramos peticiones para que se hiciera una iglesia nueva, lo que nos da entender que San Miguel era un templo que no cumplía las expectativas y se descartaba constituirlo como iglesia principal de forma definitiva, ni siquiera reformándolo. Las súplicas e informes dirigidos al rey para levantar un nuevo templo se van sucediendo repetitivamente a lo largo de todo el siglo XVI.

Los problemas de San Miguel eran su reducido tamaño y escasa monumentalidad: la necesidad de que «el sacramento esté con la reverencia que debe» y «quepa y esté la gente que allí reside» ${ }^{10}$. El 23 de marzo de 1550 se aconsejaba al rey reunir dinero para fabricar la iglesia, con impuestos y limosnas, «porque aquí no hay sino tres ermitas que apenas el domingo cabe la mitad de la gente en la mayor, que se llama San Miguel» ${ }^{11}$. El problema que se desprende de toda la documentación, era la falta de dinero para acometer las obras, llegando el veedor de la ciudad, junto al capitán e ingeniero Miguel de Perea, a recomendar al rey la necesidad de afrontar el presupuesto ${ }^{12}$. [Fig. 1]

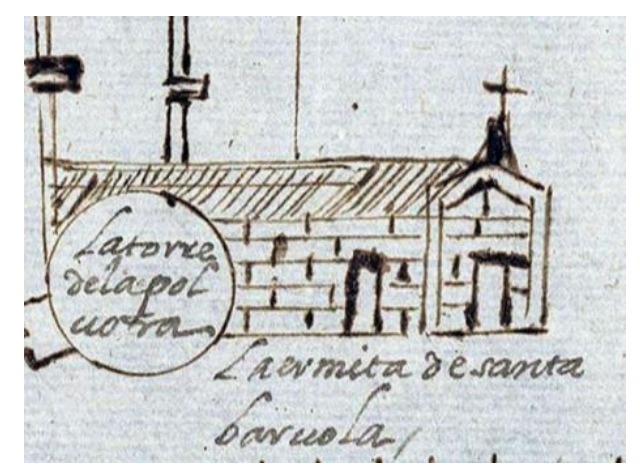

1. Dibujo de la ermita de Santa Bárvola en la Planta de la ciudad y fuerça de Melilla..., 1604. AGS, MPD, 42-065.

\footnotetext{
${ }^{10}$ AGS, GyM, leg. 39, 76 (entre 1549 y 1551).

${ }^{11}$ AGS, GyM, leg. 40, folio 33. En esta fecha ya se menciona con el título de San Miguel.

${ }^{12}$ AGS, GyM, leg.40, folio 33, 23 de marzo de 1550.
} 
En 1551, y ante esta necesidad de aumentar en lo posible y dignificar los espacios religiosos, el mismo Sancho de Escalante junto al ingeniero Miguel de Perea, realizaron en cantería la capilla de Santiago, coronada por una bóveda gótica de terceletes, en las mismas puertas de la ciudad (Bravo, 2002, p. 36-41) (Castries, 1921, p. XXIV) ${ }^{13}$. [Fig. 2]

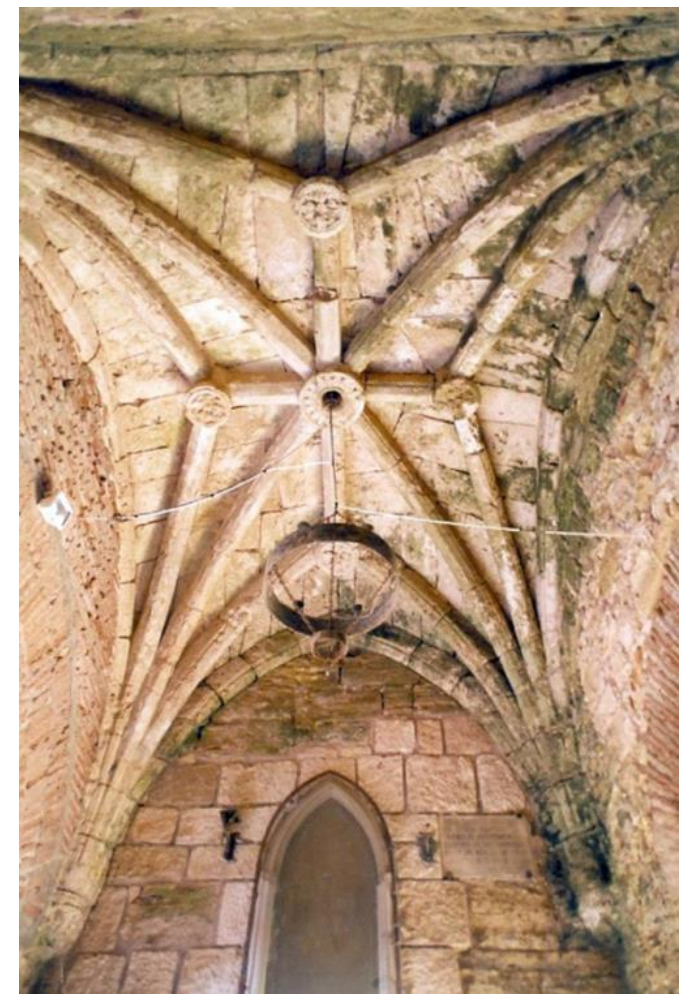

2. Capilla de Santiago de Melilla, 1551. Fotografía Antonio Bravo.

Durante la estancia en Melilla del ingeniero Zurita ${ }^{14}$ en 1553, y ante la insistencia de hacer una nueva iglesia, éste señalaba que «veré donde se podrá hacer otra, y el tamaño que ha de tener y enviaré relación», aunque una vez más no se hizo nada. Mientras tanto, lo que sí se materializó fue reparar y mejorar en lo posible la iglesia de San Miguel, que exigía permanentes reparos, como sabemos en 1562 cuando se tuvo que arreglar la armadura de madera de su techumbre, que estaba podrida ${ }^{15}$.

En 1565, persistían los problemas y se concedía limosna para reparar la iglesia de Melilla que no era otra que la ermita de San Miguel, utilizada de manera provisional como

\footnotetext{
${ }^{13}$ Carta de Alonso de Melgar al secretario Francisco de Ledesma, 15 de julio de 1553.

${ }^{14}$ AGS, GyM, leg. 51, 1553, folio 158.

${ }^{15}$ Archivo Histórico Diocesano de Málaga (AHDM), leg. 699, nº 1.
} 
templo principal por ser entonces la más grande ${ }^{16}$. El 29 de septiembre de 1566, en una instrucción que se dio a Antonio del Peso, se señalaba que la iglesia tenía pocos ornamentos religiosos y «que teniendo ordenado que se haga una iglesia», existía la posibilidad de hacerla en lugar nuevo o «si la ermita que agora sirve de iglesia es lugar suficiente para labrar la dicha iglesia, o en qué parte de la ciudad debe hacerse, y lo que sería menos costoso, edificarse de nuevo en la ermita o junto a las casas nuestras». Es entonces cuando se plantea un gran dilema, esto es, si construir la iglesia sobre la ermita de San Miguel existente, derribándola o reaprovechándola en parte, o si elegir un nuevo lugar para ello, debate que continuará hasta finales del siglo, cuando se opte por la primera opción ${ }^{17}$.

Por estos años Melilla estaba finalizando una de sus grandes obras, los aljibes, que se terminan en 1571. Un año después, el maestro mayor de las obras de Melilla, Juan de Ormaechea muere en la misma ciudad, y entonces aparece un nuevo maestro mayor, Gregorio de Arano. Según algunas fuentes, Arano llegaría en 1573, aunque una declaración del mismo, realizada en 1593, decía que llevaba 22 años continuos de maestro mayor, lo que adelantaría la fecha a 1571 (Gutiérrez, 1998-1999, p. 202).

San Miguel continuaba siendo la iglesia parroquial de Melilla, y en ella se realizaban diferentes obras que había que presupuestar. Debido a la pobreza de las aportaciones de la población, el dinero tenía que proceder de instancias oficiales. Por reales cédulas de 1562 y 1575 el rey hacía cesión de las penas de cámara (importe de multas que se imponían por determinados temas), por veinte años, para sus trabajos.

\section{Los efectos del terremoto de 1578}

En 1578 se produjo un terremoto en Melilla de gran intensidad, que afectó muy seriamente a la iglesia. En el catálogo sísmico de la península Ibérica, se recoge el seísmo que asoló Melilla en 1578. Ocurrió el 21 de octubre a las 4:00 horas, y fue catalogado como VIII en la escala macrosísmica europea EMS-1998 (Martínez y Mezcua, 2002, p. 30), que significa que fue gravemente dañino: pueden volcarse los muebles, muchos edificios corrientes sufren daños, las chimeneas se derrumban, aparecen grandes grietas

\footnotetext{
${ }^{16}$ AGS, GyM, leg 215, 185, 25 de marzo de 1565.

${ }^{17}$ AGS, GyM, leg. 72, 209, 1568.
} 
en las paredes y algunos edificios pueden derrumbarse parcialmente ${ }^{18}$. Por otra parte, hubo muchas réplicas «aun agora diez días del mes de noviembre no cesa de temblar algunas veces de día y otras de noche» ${ }^{19}$.

[Ese día] la gente acudió a la iglesia con grandes clamores de chicos y grandes a rogar a Dios fuese servido de aplacar su ira; y hallámosla que no se podía entrar dentro porque se abrió por muchas partes; y el padre vicario fray Diego de Mena dixo se saliesen fuera de la iglesia porque no hiciese daño y fue allí y le dixo que sería bien sacar el Sacramento della y al fin se acordó de lo hacer y se llevó a la plaza de San Sebastián y allí se puso una mesa donde se puso y estuvimos toda la noche rezando con el recelo que se puede considerar, pues no cesa el temblar.

Por otra parte, las obras de reparación eran imposibles porque «ni hay albañiles que las remedien que uno que había una noche antes del terremoto murió a bentestate» ${ }^{20}$. El estado de la iglesia de San Miguel es descrito en otra carta de 8 de noviembre de $1578^{21}$, donde se enumeran los desastres del terremoto: «La iglesia se ha caído la mitad por el suelo y lo que queda está desviado de una pared a otra en cantidad de manera que no puede servir de cosa alguna». En otra misiva de 10 de noviembre de 1578 se indica que hicieron una procesión con el Sacramento, poniéndose en la sala de la casa del Alcaide «donde agora está y tenemos iglesia». Por ello sabemos que se estableció allí el espacio religioso de manera provisional.

Alertado el rey de lo sucedido, pocos días después del terremoto se ordenaba enviar desde Málaga albañiles y materiales para reparar lo caído ${ }^{22}$ : «Los días pasados por el aviso que se tubo de la ruina que los temblores de la tierra hicieron en Melilla en las murallas, torres, iglesia della, se acordó que por Málaga se viajen a aquella plaza algunos albañiles, gastadores y cien soldados y materiales para alzar y reparar lo caído». También se pensó en ese momento que un ingeniero supervisara los trabajos, sobre todo los que afectaban a la fortificación: «y aquel ingeniero Juan Bautista Antonelli que asistía a la de Gibraltar fuese a la dicha Melilla [...] y vuestra merced pusiese tres mil ducados para todo y el dinero, albañiles, gastadores y materiales y de los soldados se han enviado a la

\footnotetext{
${ }_{18}$ AGS, GyM, leg. 88, 351, Lo acontecido en la ciudad de Melilla en el África.

${ }^{19} \mathrm{El}$ citado catálogo documenta dos de esas réplicas el 15 y el 17 de noviembre, produciéndose además otro terremoto importante al año siguiente, el 1 de marzo de 1579. Gabriel de Morales (1921, p. 44) sólo recoge este último, señalando que se arruinaron parte de las murallas, casa e iglesia.

${ }^{20}$ AGS, GyM, leg. 88, 351.

${ }^{21}$ AGS, GyM, leg 89, 336.

${ }^{22}$ AGS, GyM, leg. 89, 71.
} 
dicha plaza y el alcaide della escribe que estaba aguardando al Antonelli» y que «conviene que el dicho Antonelli o Jorge Fratín [...] vaya allí a trazar y dar orden en lo de los dichos reparos; porque no es bien que aquella plaza esté sin reparar».

Los albañiles, gastadores y soldados, junto a los materiales y el dinero llegaron rápidamente a Melilla, pero realmente no hemos encontrado confirmación de la llegada de los ingenieros, aunque queda clara la voluntad del rey para que visitasen la ciudad y comprobaran los efectos del seísmo. Lógicamente, uno de los edificios que hubo de ser reparado fue la iglesia de San Miguel, que debió habilitarse de manera temporal para continuar celebrando misas.

Cierto es que el terremoto agudizó la necesidad de construir el nuevo templo, de modo que sería entonces cuando se produce la decisión del rey de enviar al hermano de Jorge, Giacomo Fratín, a trazar la nueva iglesia en Melilla ${ }^{23}$. Es de señalar que Felipe II era consciente de la necesidad del nuevo templo, cuestión que comunicó al marqués de Santa Cruz: «por ser pequeña la que antes avía para oyr missa la gente que ay en ella»o al propio Fratín: «pareçe es neçesario hazer en Melilla (una iglesia), por ser pequeña la que avía en ella».

El problema de la pequeñez de San Miguel era determinante para que el rey ordenara llevar a cabo los trabajos. De todas formas, debe señalarse que el inicio de la construcción de la iglesia no se llevó a cabo inmediatamente y durante los veinte años que corren entre el terremoto de 1578 y el inicio real de las obras en 1598, las noticias sobre San Miguel son bastante imprecisas. El maestro mayor durante este periodo fue Gregorio de Arano (Gutiérrez, 1998-1999, p. 194-216) ${ }^{24}$, quien se ocuparía tanto de las obras en la vieja iglesia para intentar mantenerla en un precario uso, como de las encaminadas a realizar el templo nuevo.

Será en los últimos momentos de los años ochenta de la mencionada centuria cuando San Miguel se abandone definitivamente. En 1588 todavía seguía utilizándose de

\footnotetext{
${ }^{23}$ AGS, GyM, leg. 93, 117 y leg. 93, 120, Respuesta de carta al Marqués de Santa Cruz, para que lleve al Fratín a Melilla, necesidad de hacer una nueva Iglesia y restaurar obras tras el terremoto.

${ }^{24}$ AGS, libro 36, folio 389 y 40, Libros registro del Consejo de Guerra.
} 
alguna forma ${ }^{25}$, mientras se documentan ciertas reparaciones -aunque debieron ser las últimas $^{26}$ - con el fin de asegurar mínimamente a las personas que estuvieran en su interior.

$\mathrm{Su}$ abandono tuvo una primera consecuencia cuando antes de 1591 se tuvo que habilitar una capilla provisional, llamada la Enramada (Bravo \& Bellver, 2016, p. 389403), con una zona absidal trabajada en sillería y el cuerpo de la iglesia formado por una estructura abierta de ramas y maderas, cuya función era albergar la misa de los domingos «por estar la iglesia caída» ${ }^{27}$.

Un último aspecto sobre San Miguel tiene que ver con la decisión de construir la iglesia nueva en su mismo emplazamiento, ensanchando el espacio, o bien levantarla en otro lugar. Si se hacía en el lugar de la antigua ermita implicaba su destrucción o demolición parcial. En 1588 todavía no se tenía claro este particular ${ }^{28}$, aunque finalmente se optó por la primera opción ${ }^{29}$, siguiendo el parecer del gobernador Antonio Tejada como se expone en una carta de Felipe II al mismo ${ }^{30}$. Para ello, el 31 de junio de 1597 se compraba una casa a Juan Álvarez de Perea para ampliar el solar donde se ubicaría el nuevo templo.

\section{Vestigios actuales de la iglesia de San Miguel}

Los restos de San Miguel fueron demolidos para poder construir la nueva iglesia, pero algunos de sus elementos se reutilizaron en la obra, como delatan vestigios todavía existentes en la actualidad. De todas formas, no parece que se pudieran haber aprovechado muchos motivos de la vieja ermita, por cuanto la fábrica del nuevo templo tiene una gran unidad arquitectónica. No obstante, sí que pudieron integrarse algunas estructuras aisladas tales como muros o $\operatorname{arcos}^{31}$.

\footnotetext{
${ }^{25}$ AGS, GyM, leg. 225, 357, 3 de julio de 1588, Carta de Juan Bautista de la Oliva, vicario de Melilla, suplicando se ordene construir una iglesia por no haberla y usarse una ermita con la que no se da abasto.

${ }^{26}$ AGS, GyM, leg 302, 38, 7 de diciembre de 1590. Aparecen apuntes económicos de lo que se debe en obras y corresponden desde 1582 a 1589; en ellos figuran partidas de la iglesia de San Miguel.

${ }^{27}$ AGS, GyM, leg. 353, 132, 29 de abril de 1592. Relación del tanteo que se tomó al pagador Juan Álvarez de Aguilar de los maravedies del rey de quintos de cabalgadas y derechos de puertas y hierros desde 1 de enero de 1585 hasta fin de diciembre de 1591.

${ }^{28}$ AGS, GyM, leg. 225, 354, 3 de julio de1588 y GyM, leg. 225, 356, 7 de julio de 1588.

${ }^{29}$ H. de Lázaro (1918, s. p.) opinaba que la antigua San Miguel estaba situada en el lugar que ocupa la capilla mayor del actual templo parroquial (se trataba de la capilla de San Miguel Arcángel, usada como parroquia).

${ }^{30}$ AGS, GyM, leg. 231, 290, 30 de julio de 1588, Minuta de carta de Su Majestad Felipe II, a Antonio de Tejeda, capitán de Melilla.

${ }^{31}$ El acercamiento arqueológico y documental a esta arquitectura evidencia una falta de unidad respecto a otros ejemplos existentes en el norte de África, pero abre las puertas a una vía de investigación futura a otros edificios de similar tamaño con los que debería compartir, a buen seguro, soluciones formales y problemática constructiva similares.
} 
La localización de estos vestigios no es tarea fácil. En el pasado se han podido documentar algunos durante las diferentes obras de restauración del edificio. Sólo en el transcurso de las reparaciones llevadas a cabo en 1992, y al retirar el enfoscado de uno de los muros en la actual capilla del Nazareno y de las Ánimas (anteriormente capilla de la Encarnación), pudo obtenerse una fotografía que delataba la existencia de un arco ojival, aparentemente reaprovechado, mostrando su intradós macizado en el muro y sobre el que se había superpuesto de forma asimétrica una puerta con decoración mudéjar del siglo XVIII. Durante esas obras no hubo seguimiento arqueológico alguno, por lo que no se pudo investigar dicho arco, quedando la fotografía como un documento imprescindible que posibilitaría actuaciones posteriores. [Fig. 3]

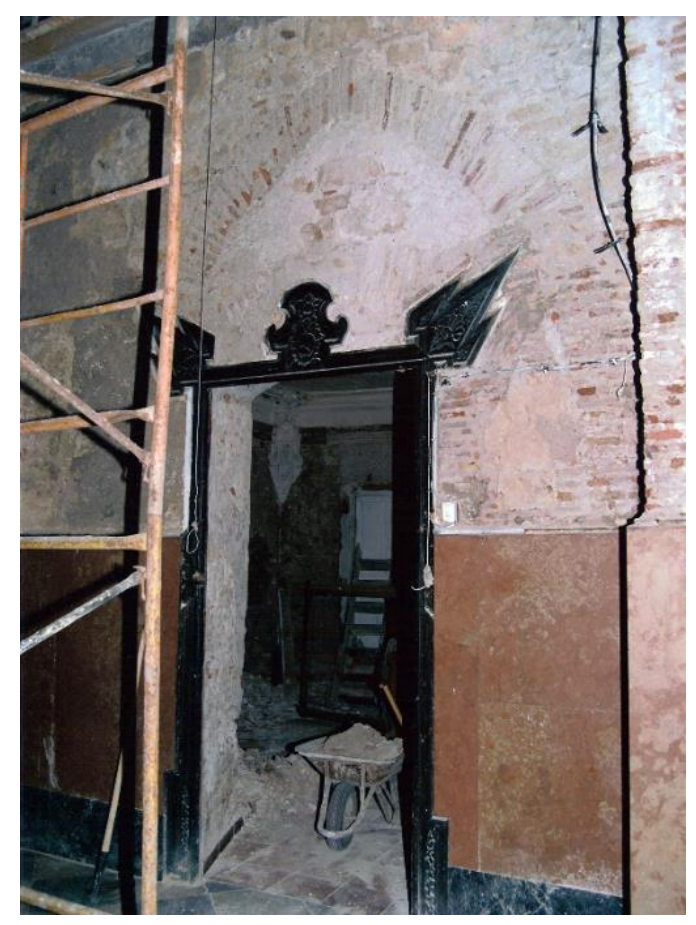

3. Fotografía de las obras de la iglesia, 29 de abril de 1992. Cedida en su momento por el Director Provincial de Cultura de Melilla.

Por esta razón, al acometerse 25 años después unas obras de urgencia, como consecuencia del terremoto que sufrió Melilla en enero de 2016, pudimos informar y recomendar al arquitecto José Antonio Fernández Fernández, director de las obras, sobre su existencia y la importancia de su posible recuperación. Con el inicio de los trabajos en 2017 se actuó en ese paño de muro, de tal forma que al retirar una gruesa capa de 
enfoscado moderno (cemento y pintura) aparecía una rosca de ladrillo correspondiente a un aparente arco ojival. [Fig. 4]

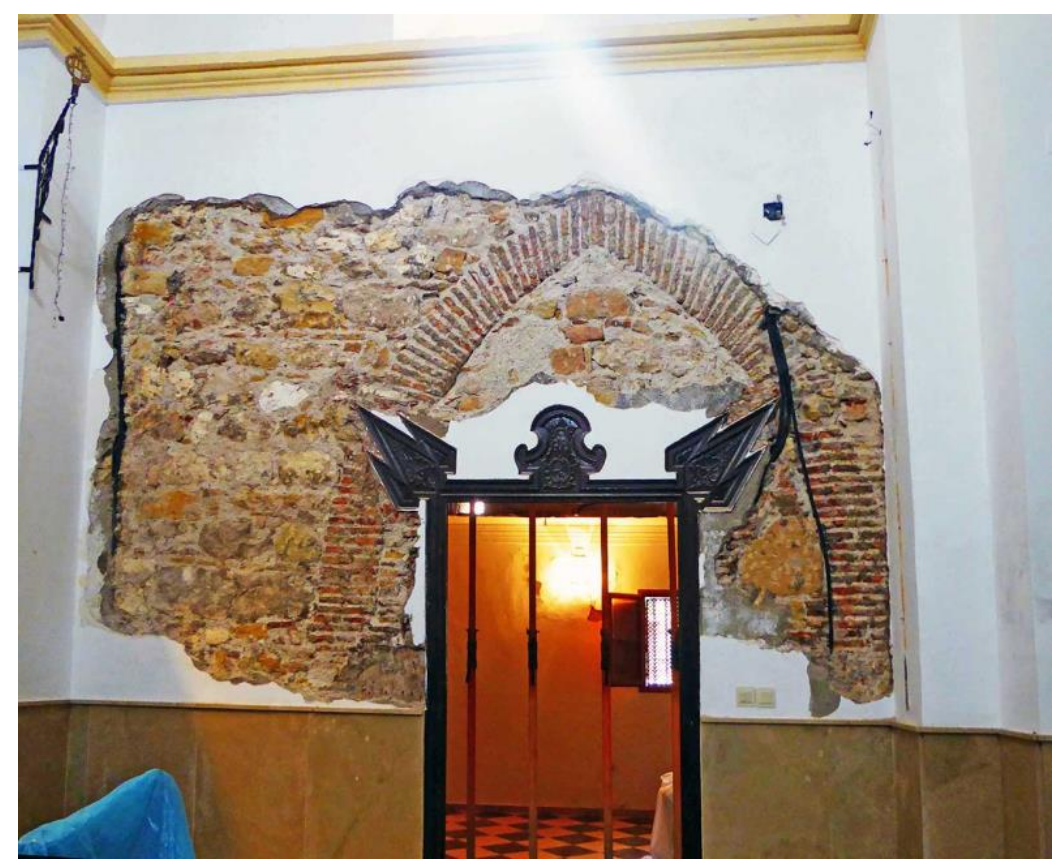

4. Frontal del arco ojival al retirarse el enfoscado, 23 de abril de 2016. Fotografía Antonio Bravo.

Con el desmontaje de la puerta del siglo XVIII y al suprimirse el muro macizado en su intradós, pudo comprobarse que efectivamente se trataba de un arco de ladrillo completo, ojival, de gran potencia. El arco se sitúa en un muro de la citada capilla del Nazareno, y no guarda relación de simetría con la estructura actual, por lo que redobla la hipótesis de un reaprovechamiento de estructuras anteriores. Como la iglesia nueva que se comienza a finales del XVI sigue unos modelos ligados por completo al Manierismo, y donde no aparece ningún elemento de vinculación gótica, es totalmente descartable que forme parte de ese proyecto. Esto ligaría lógicamente la estructura con la obra anterior, en concreto con la ermita-iglesia de San Miguel.

A pesar de que esta última obra contaba con seguimiento arqueológico, su carácter de urgencia no permitió analizar otros aspectos de esta composición, como la búsqueda bajo la solería actual de posibles restos de muros o estructuras ahora ocultos, lo que debería ser acometido en unos futuros trabajos que se programan acometer a lo largo del año 2021. [Fig. 5] 


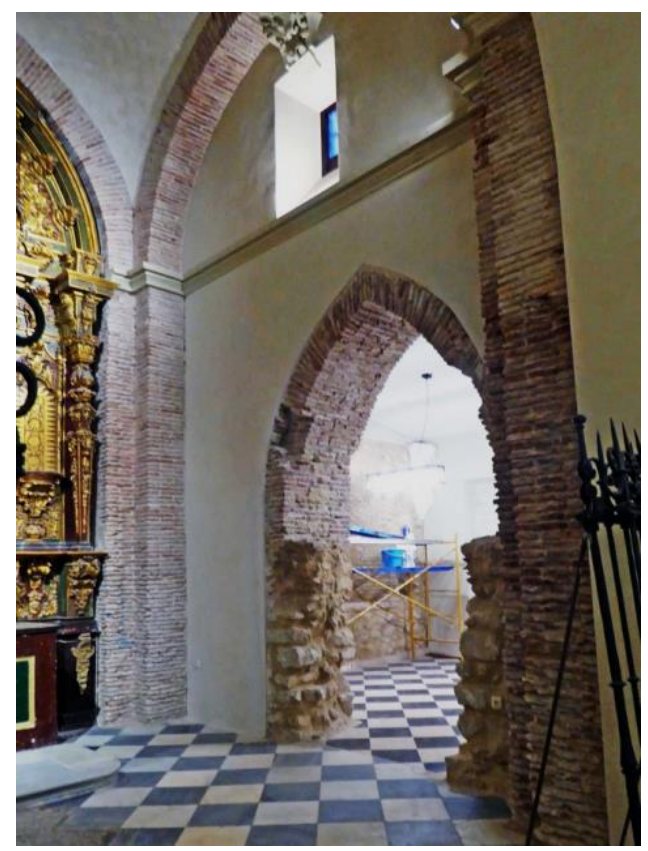

5. El arco ojival ya recuperado en su totalidad, 3 de abril de 2017. Fotografía Antonio Bravo.

Otra parte de la construcción que no parece pertenecer a la estructura de la iglesia que se construye a partir de 1598 , es un saliente de sillería existente en el patio trasero junto al ábside de la iglesia, en la zona del evangelio (muy cercano al arco) y que debería ser estudiado con interpretación arqueológica para delatar posibles conexiones con la iglesia de San Miguel. [Fig. 6]

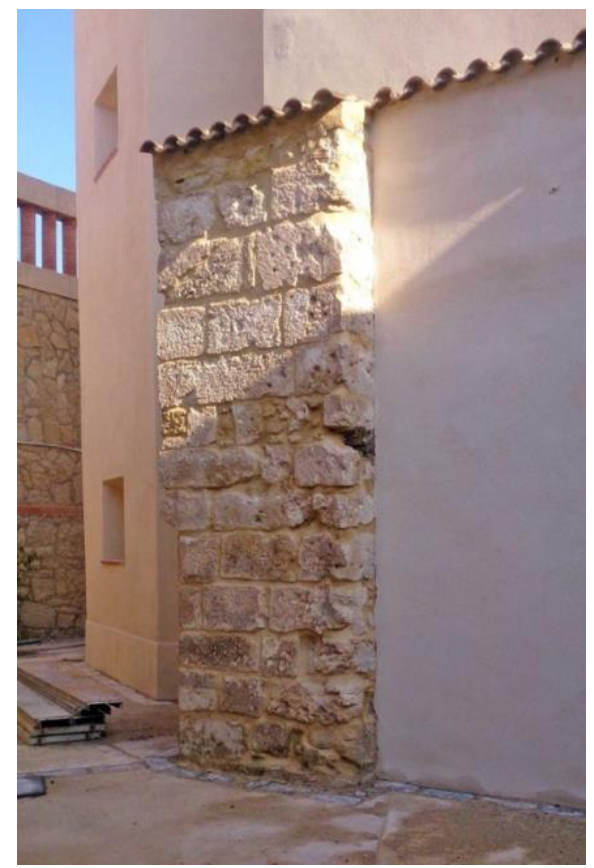

6. Estructura de sillería en la zona de la cabecera de la iglesia, 5 de abril de 2017. Fotografía Antonio 
Desde luego, la existencia del arco ojival en la zona de la capilla del Nazareno manifiesta claramente la dependencia de la primitiva iglesia de San Miguel con esta zona del actual templo. Considerando las reducidas dimensiones de aquel primer inmueble y su más que probable conformación a través de una nave única o de cajón, en la línea del resto de ermitas de la ciudad y como reflejo de un modelo muy difundido en la época, pueden manifestarse diferentes hipótesis acerca de la orientación y compostura final dentro del desconocido entramado urbano del momento.

Como ya vimos, el 23 de marzo de 1550 se decía que en ella cabía a duras penas la mitad de la población de Melilla ${ }^{32}$. Si la población total en ese año era de 551 personas (Salafranca, 1987, p. 163), puede aventurarse como aproximación que San Miguel podría acoger a unas 250 personas, lo que nos lleva a una superficie, siempre como hipótesis muy aproximativa, de entre 200 a 300 metros cuadrados en lo que respecta a su nave principal.

El conocimiento de la función del arco gótico sería la clave para esclarecer si pertenecía al ingreso al recinto o si daba acceso a una capilla probablemente en la zona de la cabecera. De ello, dependería también la orientación perpendicular o transversal de su nave, lo que debe ser confirmado con prospecciones arqueológicas que busquen rastros ocultos del antiguo edificio.

\section{Conclusiones}

Estudiar las características de la primera iglesia de San Miguel de Melilla nos permite conocer los rasgos principales que caracterizaban la construcción de un edificio religioso en la llamada frontera norteafricana, que los primeros Habsburgo mantuvieron durante todo el siglo XVI. Frontera en la que los aspectos religiosos desempeñaron obviamente un papel muy destacado, y que por tanto exigía la existencia de edificios dignos para el culto cristiano que fueron costeados por los mismos reyes.

Las peculiaridades de su ubicación norteafricana y en una ciudad fuerte de frontera, determinaron un esquema de trabajo singular, establecido sobre la dual

${ }^{32}$ AGS, GyM, leg. 40, folio 33. 
estructura técnica de ingenieros que trazaban las obras y maestros mayores que las ejecutaban y hacían los trabajos secundarios.

Su cronología también nos sitúa ante otra singularidad, como fue la pervivencia de un gótico tardío que podemos encontrar en muy contados casos en el continente africano. Por todo ello, estudiar esta pequeña iglesia nos permite abordar varias singularidades: tanto la forma concreta de trabajo en una ciudad fortificada de frontera, como la pervivencia del estilo gótico en la primera mitad del siglo XVI.

\section{Referencias bibliográficas}

Blasco López, José Luis (consultado 2020). Presencia de las órdenes religiosas e iglesia católica en el norte de África: el cristianismo en Melilla (obra inédita sin publicar).

- (1989), Aportación documental para un profundo estudio del conjunto monumental formado por la real iglesia de la Concepción y conventico de capuchinos. Publicaciones de la escuela universitaria del profesorado de E.G.B. de Melilla, $\mathrm{n}^{\mathrm{o}}$ 16, pp. $27-56$.

Blasco López, José Luis y Manuel L. Peregrina Palomares (2001), Aportación documental para datar la iglesia de San Miguel en Melilla la Vieja. Cuadernos de Arte,

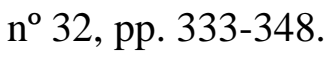

Bravo Nieto, Antonio (1991). Ingenieros militares en Melilla, teoría y práctica de fortificación en la edad moderna. UNED: Melilla.

- (2002), Tradición y modernidad en el Renacimiento español: la Puerta y capilla de Santiago de Melilla. Akros. La revista del Museo, nº 1, pp. 36-41.

- (2013), Sancho de Escalante. En Diccionario Biográfico Español, XVII (pp. 4514529. Madrid, Real Academia de la Historia.

Bravo Nieto, Antonio y Juan Antonio Bellver Garrido (2016), Una tipología arquitectónica inédita en el norte de África. La capilla de la Ramada de Melilla. En Teixeira, André. Entre les deux rives du détroit de Gibraltar, archéologie de frontères aux 14-16 siècles (pp. 389-403). Lisboa: Centro de Historia d'Aquém e d'Além- Mar. 
Carabelli, Romeo (2012). L'heritage portugais au Maroc, un patrimoine d'actualité. Mutual Heritage.

Castries, Henry de (1921). Les sources inedites de l'histoire du Maroc, t. I. Editions Ernest Leroux: París.

Correia, Jorge y André Teixeira (coords.) (2019). A península Ibérica e o norte de África (séculos XV a XVII). História e Património. CHAM Centro de Humanidades, Facultade de Ciências Sociais e Humanas: Lisboa.

Darias Príncipe, Alberto (2012), La ruta cultural de las fortificaciones hispano portuguesas en la costa atlántica marroquí. Quintana, n 11, pp. 139-148.

Estrada, Juan A. de (1768). Población general de España, sus reynos, y provincias, ciudades, villas, y pueblos, islas adyacentes, y presidios de África, tomo II. Imprenta de Andrés Ramírez: Madrid.

Fernández de Castro y Pedrera, Rafael (1941). Resumen histórico del patronazgo de María Santísima de la Victoria, excelsa patrona de Melilla, y breve historial de las antiguas iglesias y ermitas de la ciudad de Melilla (siglos XVI al XX). Instituto General Franco: Tánger.

González Sánchez, Vidal (2001), El servicio religioso en una ciudad de avanzadilla de la cristiandad: el antiguo templo parroquial: sus vicisitudes. Su progresivo deterioro a través de los siglos y los repetidos intentos de restauración, hasta la construcción del nuevo templo en la Concepción de Nuestra Señora, en Melilla. Isla de Arriarán, nº 17, pp. 4970.

Gutiérrez Cruz, Rafael (1993), Melilla tras la conquista: documentos para su estudio. Aldaba, no 21, I-1, pp. 81-115.

- (1998-1999), Fuentes para la historia de Melilla en el Archivo General de Simancas, El Vigía de Tierra, no 4-5, pp. 175-216.

Lázaro, H. de (1918), Cartas de Melilla. Revista El Adalid Seráfico, nº 7, s. p.

Martínez Solares, José Manuel y Julio Mezcua Rodríguez (2002). Catálogo sísmico de la Península Ibérica (880 a. C.-1900). Ministerio de Fomento: Madrid. 
Mendes Paula, Frederico (2019). Histórias de Portugal em Marrocos. Argumentum: Lisboa.

Morales y Mendigutía, Gabriel de (1921). Efemérides y curiosidades. Melilla, Peñón y Alhucemas. Tipografía El Telegrama del Rif: Melilla.

Ramírez González, Sergio (2013). El triunfo de la Melilla Barroca. Arquitectura y arte. Fundación Gaselec: Melilla.

- (2014), La iglesia de la Purísima Concepción de Melilla: nuevos descubrimientos en torno a las fases de su construcción. Akros, n 13, pp. 17-24.

Ramírez González, Sergio y Antonio Bravo Nieto (2020), Reformas en la capilla mayor de la iglesia de la Victoria de Orán (Argelia): el patronazgo del ingeniero militar Juan Martín Zermeño. De Arte. Revista de Historia del Arte, nº 19, (en prensa).

Ramos, Luis F. et al. (2010), Safeguarding of the Portuguese Heritage: the Case Study of Safi Cathedral, Morocco, recurso consultado el 5 de junio de 2020: https://www.researchgate.net/publication/264119245_Safeguarding_of_the_Portuguese _heritage_the_case_study_of_Safi_Cathedral_Morocco

Salafranca Ortega, Jesús F. (1985), Fuentes documentales para la historia de Melilla: la vicaría de África del Archivo Diocesano de Málaga. Aldaba, no 5, pp. 191-197.

- (1987), Bosquejo histórico de la población y guarnición de Melilla (1497-1874). Ayuntamiento: Melilla. 